\title{
ANALISIS CAMPURAN SEMEN DAN SERBUK BATU BATA SEBAGAI PENGIKAT TANAH GAMBUT TERHADAP SUBGRADE
}

\author{
Ir. Nuryasin abd, M.Si \\ Dosen Program Studi Teknik Sipil Sekolah Tinggi Teknologi Dumai \\ Jl. Utama Karya Bukit Batrem II \\ Email : yasinabdillah10@gmail.com
}

\begin{abstract}
ABSTRAK
Kondisi jalan dikota dumai sering mengalami kerusakan pada struktur lapisan permukaan jalan, lapisan permukaan jalan mengalami kembang susut sehingga menyebabkan jalan menjadi retak-retak bahkan berlubang. Untuk mengatasi permasalahan tersebut salah satu cara atau metode yang digunakan adalah memperbaiki kualitas tanah asli. Oleh karena itu dalam penelitian ini dilakukan stabilisasi tanah dengan cara memperbaiki gradasinya yaitu mencampur tanah gambut (tanah asli) dengan semen PCC dan serbuk batu bata. Dalam penelitian ini dilakukan pengujian laboratorium yaitu uji sifat fisik tanah untuk mengetahui kadar air dan berat jenis. Kemudian dilakukan uji sifat mekanis tanah dengan modifikasi proktor dan CBR Laboratorium. Dengan bahan campuran modifikasi yaitu modifikasi $10 \%$ semen dan $15 \%$ serbuk batu bata, $15 \%$ semen dan $20 \%$ serbuk batu bata, $20 \%$ semen dan $25 \%$ serbuk batu bata, $0 \%$ semen dan serbuk batu bata. Kemudian hasil penelitian yang telah dilakukan tanah yang telah dimodifikasi dengan campuran semen $15 \%$ dan serbuk batu bata $20 \%$ didapatkan nilai tertinggi CBR Laboratorium yaitu sebesar $25.88 \%$. Sehingga dapat disimpulkan bahwa tanah gambut yang telah dimodifikasi dengan campuran semen 15\% dan serbuk batu bata $20 \%$ dapat diaplikasikan sebagai pengikat subgrade dilapangan.
\end{abstract}

Kata kunci : Semen PCC, Serbuk Batu Bata, Stabilisasi

\begin{abstract}
Road conditions in the city of Dumai often experience damage to the structure of the road surface layer, the surface layer of the road undergoes shrinkage, causing the road to become cracked and even hollow. To overcome these problems one method or method used is to improve the quality of native soil. Therefore in this study soil stabilization was carried out by improving the gradation of mixing peat soil (native soil) with PCC cement and brick powder. In this study laboratory testing is carried out by testing the physical properties of the soil to determine moisture content and specific gravity. Then the mechanical properties of the soil were tested by modifying the procurator and CBR Laboratory. With the modified mixture, the modification is $10 \%$ cement and $15 \%$ brick powder, $15 \%$ cement and $20 \%$ brick powder, $20 \%$ cement and $25 \%$ brick powder, $0 \%$ cement and brick powder. Then the results of research that has been carried out on modified soil with a mixture of $15 \%$ cement and $20 \%$ brick powder obtained the highest CBR Laboratory value of $25.88 \%$. It can be concluded that modified peat soil with a mixture of $15 \%$ cement and $20 \%$ brick powder can be applied as a subgrade binder in the field.
\end{abstract}

Keywords: PCC cement, brick powder, stabilization 


\section{PENDAHULUAN}

Dumai sebagian terdiri dari daratan rendah di bagian utara dan di sebelah selatan sebagian adalah daratan tinggi, kondisi tanahnya mayoritas berupa tanah rawa yang bergambut dengan kedalaman antara 0-3 $\mathrm{m}$. Struktur tanah umumnya terdiri dari tanah podsolik merah kuning dari batuan endapan, alluvial dan tanah organosol dan gley humus dalam bentuk rawa-rawa atau tanah basah.

Tanah dasar (subgrade) adalah bagian terpenting dalam pembangunan, terutama untuk pembangunan jalan. Dimana sarana infrastruktur jalan nantinya mempunyai peran yang sangat penting dalam menunjang pertumbuhan ekonomi di masyarakat. Perbaikan mutu sarana jalan dilakukan dengan perencanaan lapis perkerasan yang baik serta memperhatikan tanah dasar (subgrade). Kondisi jalan sering mengalami kerusakan pada struktur lapisan permukaan jalan, lapisan permukaan jalan mengalami kembang susut sehingga menyebabkan jalan menjadi retak-retak bahkan berlubang.

Dengan adanya permasalahan seperti diatas dapat menjadi dasar dalam penelitian ini. Untuk mengatasi permasalahan tersebut salah satu cara atau metode yang digunakan adalah memperbaiki kualitas tanah asli (stabilisasi). Penambahan material berbutir kasar pada material tanah gambut akan mengakibatkan perubahan pada sifat pengembangan tanah dan peningkatan daya dukung tanah, oleh karena itu dalam penelitian ini dilakukan stabilisasi tanah dengan cara memperbaiki gradasinya yaitu mencampur tanah gambut (tanah asli) dengan serbuk batu bata .

Sifat-sifat tanah dapat diperbaiki secara ekonomis dengan menggunakan bahan campuran. Salah satu bahan campuran yang dapat digunakan sebagai bahan stabilisasi adalah semen PCC, mengingat bahwa kemampuannya mengeras dan mengikat butir-butir agregat sangat baik. Hal ini bermanfaat bagi usaha mendapatkan massa tanah yang kokoh.

Semen PCC dapat bereaksi dengan hampir semua jenis tanah, dari jenis kasar nonkohesif sampai sangat plastis. Biasanya pada stabilisasi tanah dasar dengan menggunakan semen $P C C$ ditambahkan suatu retarder ganti bahan untuk memperlambat pengerasan. Bahan yang digunakan adalah serbuk batu bata dan semen PCC.

\section{LANDASAN TEORI}

Tanah gambut (peat) termasuk tanah organik, secara visual terlihat sebagai massa berserat mengandung kekayuan, biasanya berwarna gelap dan berbau tumbuhan yang membusuk.Tanah ini mengandung bahan organik yang tinggi mempunyai kuat geser yang rendah, mudah mampat dan bersifat asam yang dapat merusak material bangunan. Meskipun demikian, dengan berbagai alasan dan pertimbangan pekerjaan konstruksi diatas endapan gambut sering terpaksa dilakukan, terutama untuk pembangunan daerah pemukiman dan jalur jalan raya seperti yang ada di daerah Sumatera, Kalimantan dan Papua (Teguh Nugroho dan Budi Mulyanto, 2003). 
Seorang insinyur sipil menganggap tanah termasuk semua bahan, organik dan anorganik, yang ada di atas lapisan batuan tetap (Dunn dkk., 1980). Menurut Craig (1991), tanah adalah akumulasi mineral yang tidak mempunyai atau lemah ikatan antar partikelnya, yang terbentuk karena pelapukan dari batuan. Tanah didefinisikan oleh Das (1995) sebagai material yang terdiri dari agregat mineralmineral padat yang tidak tersementasi (terikat secara kimia) satu sama lain dan dari bahan-bahan organik telah melapuk (yang berpartikel padat) disertai dengan zat cair dan gas yang mengisi ruang-ruang kosong diantara partikel-partikel padat tersebut. Menurut Bowles (1984), tanah adalah campuran partikel-partikel yang terdiri dari salah satu atau seluruh jenis berikut :

a. Berangkal (boulders) adalah potongan batuan yang besar, biasanya lebih besar dari 250 sampai $300 \mathrm{~mm}$ dan untuk ukuran $150 \mathrm{~mm}$ sampai $250 \mathrm{~mm}$, fragmen batuan ini disebut kerakal (cobbles/pebbles).

b. Kerikil (gravel) adalah partikel batuan yang berukuran $5 \mathrm{~mm}$ sampai $150 \mathrm{~mm}$.

c. Pasir (sand) adalah partikel batuan yang berukuran $0,074 \mathrm{~mm}$ sampai $5 \mathrm{~mm}$, yang berkisar dari kasar dengan ukuran $3 \mathrm{~mm}$ sampai $5 \mathrm{~mm}$ sampai bahan halus yang berukuran $<1 \mathrm{~mm}$.

d. Lanau (silt) adalah partikel batuan yang berukuran dari 0,002 $\mathrm{mm}$ sampai $0,0074 \mathrm{~mm}$.

e. Lempung (clay) adalah partikel mineral yang berukuran yang kohesif.

f. Koloid (colloids) adalah partikel mineral yang diam dan berukuran lebih kecil dari $0,001 \mathrm{~mm}$.

\section{METODE PENELITIAN}

\section{Jenis Metode}

Dalam penelitian ini jenis metode yang digunakan ialah metode eksperimen, yaitu penelitian yang tujuannya untuk meneliti atau menyelidiki hubungan sebab akibat satu dengan lainnya dan membandingkan hasilnya. Adapun pengujian yang dilakukan dalam penelitian ini yaitu pengujian Hand Bor. Pengujian yang dilakukan mengacu pada standart ASTM.

\section{Lokasi Penelitian}

Penelitian dilaksanakan di laboratorium mekanika tanah Sekolah Tinggi Teknologi Dumai.

\section{Bahan Penelitian}

Bahan penelitian yang digunakan dalam melakukan penelitian ini ialah tanah gambut pada lokasi daerah Jayamukti, serbuk batu bata pada lokasi kelurahan Purnama, semen PCC, yang berada di Kota Dumai. 


\section{Variabel Penelitian}

Variable penelitian adalah segala sesuatu yang akan menjadi objek pengamatan penelitian. Dapat juga diartikan sebagai factor-faktor yang berperan penting dalam peristiwa atau gejala yang akan diteliti. Dapat dilihat pada Flow Chart dibawah ini.

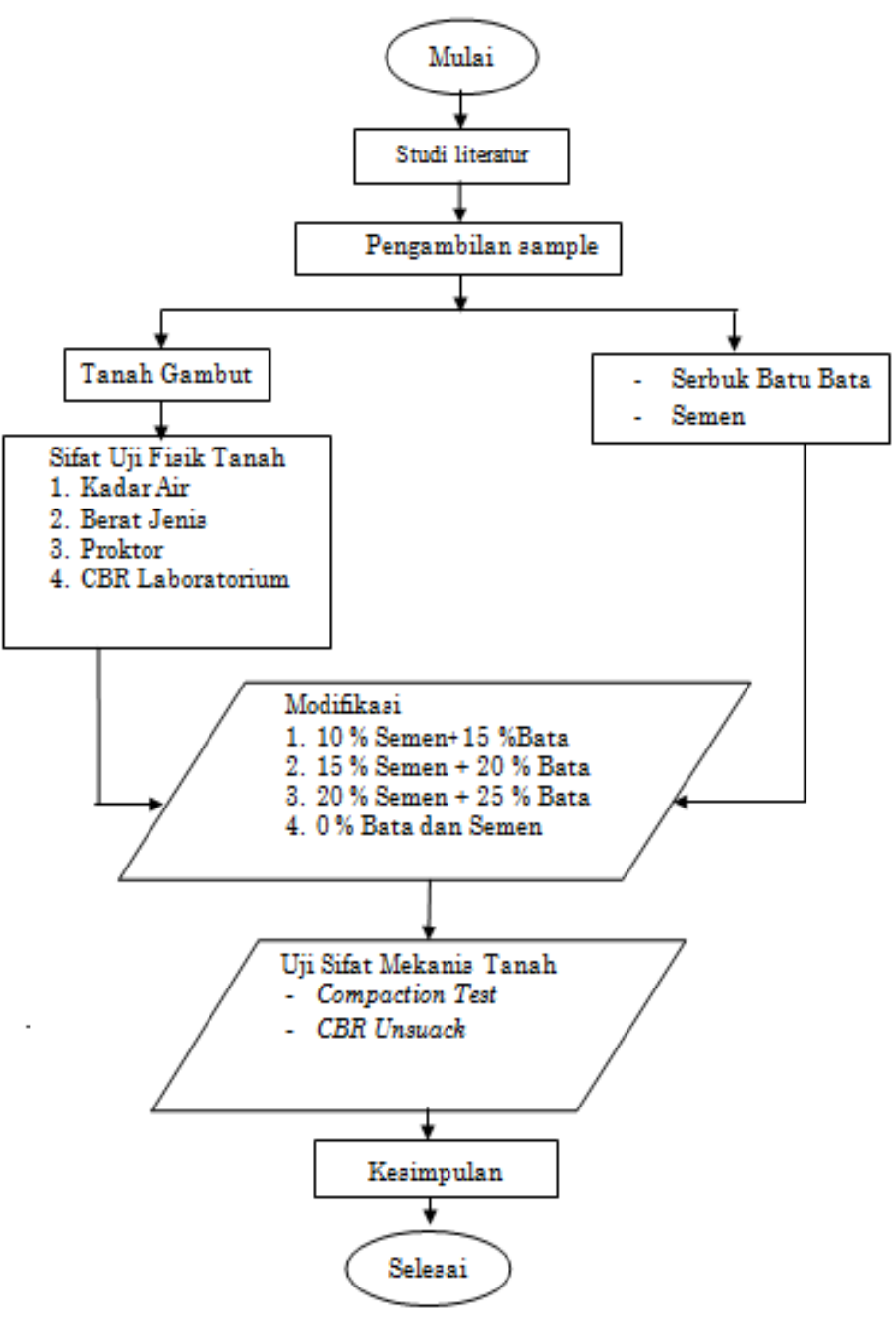

Gambar 1. Flow Chart Penelitian

Sumber : Penelitian 2017

\section{HASIL PEMBAHASAN}

\section{Umum}

Dalam bab ini peneliti akan menjelaskan mengenai hasil-hasil pengujian yang diantaranya adalah pengujian kadar air tanah, berat jenis tanah, analisa saringan serbuk batu bata, pengujian proktor dan CBR laboratorium. Bahan untuk pengujian 
modifikasi yaitu tanah gambut, semen, dan serbuk batu bata. Pengujian ini dilakukan di Laboratorium Geoteknik Teknik Sipil Sekolah Tinggi Teknologi Dumai .

\section{Pengujian Karakteristik Tanah}

Pengujian tanah di laboratorium dilakukan terhadap semua contoh tanah yang diperoleh dari lapangan berupa contoh tanah terganggu dan contoh tanah tidak terganggu. Pengujian-pengujian yang dilakukan bertujuan untuk memperoleh data dan informasi parameter sifat fisik maupun sifat mekanika tanah, selanjutnya parameter-parameter tersebut akan digunakan sebagai bahan analisis dan pertimbangan dalam perencanaan dan desain tipe penanganan modifikasi tanah.

\section{Pengujian Karakteristik Tanah Gambut (0\%)}

Dari hasil penelitian diperoleh hasil pengujian sifat fisik tanah gambut seperti pada tabel 1. berikut ini.

Tabel 1 Hasil Pemeriksaan Kadar Air Tanah Gambut

\begin{tabular}{|lcc|c|c|c|c|}
\hline Data Benda Uji & & 1 & 2 & 3 & 4 \\
\hline Berat Isi Basah + Cawan & W1 & (gram) & 55 & 37 & 35 & 35 \\
Berat Isi Kering + Cawan & W2 & (gram) & 33.5 & 24.5 & 24 & 23.5 \\
Berat Cawan & W3 & (gram) & 8.5 & 9 & 8.5 & 9 \\
Berat Air & W1-W2 & (gram) & 21.5 & 12.5 & 11 & 11.5 \\
Berat Tanah Kering & W2-W3 & (gram) & 25 & 15.5 & 15.5 & 14.5 \\
\hline Kadar Air & & $\%$ & 86 & 80.65 & 70.97 & 79.31 \\
\hline
\end{tabular}

Sumber : Hasil Penelitian (2017)

Hasil Pemeriksaan kadar air tanah sebesar $86 \%$, nilai tersebut termasuk rendah dikarenakan sifat tanah gambut yang telah diketahui yaitu mampu menahan atau menyimpan air hingga 500\%.

Tabel 2. Hasil Pemeriksaan Sifat Fisik Tanah Gambut

\begin{tabular}{|c|l|c|c|c|c|}
\hline No & Pemeriksaan & Hasil & Standart & Satuan & Acuan \\
\hline 1 & Kadar Air Tanah & 86 & $500 \%$ & $\%$ & ASTM \\
\hline 2 & Berat Jenis Tanah & 2.6 & $2.4-2.8$ & gram & ASTM \\
\hline
\end{tabular}

Sumber : Hasil Penelitian (2017) 
Kemudian berdasarkan hasil pemeriksaan sifat fisik tanah gambut diperoleh jumlah berat jenis (picnometer) sebesar 2.60 gram, berat jenis tanah ini memenuhi standar spesifikasi berat jenis tanah yaitu $2.4-2.8$.

Berikut ini adalah hasil data pemeriksaan kepadatan tanah gambut asli tanpa campuran semen dan serbuk batu bata.

Tabel 3 Hasil pemeriksaan kepadatan tanah gambut

\begin{tabular}{|l|l|l|l|l|}
\hline No & \multicolumn{1}{|c|}{ Pemeriksaan } & Hasil & Satuan & Acuan \\
\hline 1 & Tanah gambut & & & \\
\hline & a. Woptimum & 18.50 & $\%$ & \multirow{2}{*}{ ASTM } \\
\hline & b.rdmax & 1.25 & $\mathrm{gr} / \mathrm{cm}^{3}$ & \\
\cline { 1 - 4 } & c. $95 \%$ rd max & 1.19 & $\mathrm{gr} / \mathrm{cm}^{3}$ & \\
\hline
\end{tabular}

Sumber : Hasil Penelitian (2017)

Didapatkan kesimpulan pada hasil pemeriksaan kepadatan tanah gambut asli (0\%) tanpa campuran semen dan serbuk batu bata didapatkan nilai Woptimum sebesar $18.50 \%$.

\section{Uji Karakteristik Tanah Campuran}

Dari hasil penelitian yang telah dilakukan diperoleh sifat mekanis tanah dengan modifikasi menggunakan semen PCC dan serbuk batu bata dengan cara pemadatan (proctor), dan menentukan nilai CBR Laboratorium, berikut ini adalah tabel hasil uji pemadatan (proctor) dan CBR Laboratorium.

Tabel 4. Hasil pemeriksaan uji modifikasi pemadatan (proctor)

\begin{tabular}{|c|c|c|c|c|}
\hline No & Pemeriksaan & Hasil & Satuan & Acuan \\
\hline \multirow[t]{4}{*}{1} & Campuran semen $10 \%+15 \%$ serbuk batu bata & & & \multirow{7}{*}{ ASTM } \\
\hline & a. Woptimum & 12.00 & $\%$ & \\
\hline & b.rdmax & 1.42 & $\mathrm{gr} / \mathrm{cm}^{3}$ & \\
\hline & c. $95 \%$ rd $\max$ & 1.35 & $\mathrm{gr} / \mathrm{cm}^{3}$ & \\
\hline \multirow[t]{3}{*}{2} & Campuran semen $15 \%+20 \%$ serbuk batu bata & & & \\
\hline & a. Woptimum & 13.00 & $\%$ & \\
\hline & b.rdmax & 1.40 & $\mathrm{gr} / \mathrm{cm}^{3}$ & \\
\hline
\end{tabular}




\begin{tabular}{|l|l|l|l|}
\hline & c. $95 \%$ rd max & 1.33 & $\mathrm{gr} / \mathrm{cm}^{3}$ \\
\hline 3 & Campuran semen $20 \%+25 \%$ serbuk batu bata & & \\
\hline & a. Woptimum & 15.70 & $\%$ \\
\hline & b.rdmax & 1.42 & $\mathrm{gr} / \mathrm{cm}^{3}$ \\
\hline & c. $95 \%$ rd max & 1.35 & $\mathrm{gr} / \mathrm{cm}^{3}$ \\
\hline
\end{tabular}

Sumber : Hasil penelitian (2017)

Dari data modifikasi proktor diatas didapat hasil Woptimum tertinggi dari campuran semen $20 \%+25 \%$ serbuk batu bata dengan nilai $15.70 \%$.

Berikut ini adalah hasil dari uji CBR Laboratorium dengan modifikasi tanah gambut dengan semen dan serbuk batu bata.

Tabel 5. Hasil pemeriksaan modifikasi CBR Laboratorium

\begin{tabular}{|l|l|c|c|c|}
\hline No & \multicolumn{1}{|c|}{ Pemeriksaan } & Hasil & Satuan & Acuan \\
\hline 1 & $\begin{array}{l}\text { Campuran semen } 10 \%+15 \% \text { serbuk batu bata } \\
\text { a. } 0.2\end{array}$ & & \\
\cline { 1 - 3 } & & 3.80 & $\%$ \\
\hline 2 & Campuran semen $15 \%+20 \%$ serbuk batu bata & 25.88 & $\%$ \\
\hline 3 & a. 0.2 & & \\
\hline & Campuran semen $20 \%+25 \%$ serbuk batu bata & 20.36 & $\%$ \\
\hline 4 & Campuran semen $0 \%+0 \%$ serbuk batu bata & - & - & \\
\hline
\end{tabular}

Sumber : Hasil penelitian (2017)

Dari data yang didapatkan pada uji CBR Laboratorium didapatkan hasil tertinggi CBR Laboratorium adalah senilai $25.88 \%$ dengan campuran semen $15 \%$ dan $20 \%$ serbuk batu bata. Pengujian modifikasi CBR Laboratorium berdasarkan acuan ASTM.

\section{KESIMPULAN DAN SARAN}

\section{Kesimpulan}

Dari hasil penelitian yang telah dilakukan dapat disimpulkan bahwa :

1. Tanah yang telah dimodifikasi dengan campuran semen $15 \%$ dan serbuk batu bata $20 \%$ dapat meningkatkan daya dukung tanah gambut dengan nilai CBR Laboratorium tertinggi adalah sebesar $25.88 \%$.

2. Perbandingan tanah asli gambut dan tanah yang telah dimodifikasi, yaitu pada tanah gambut asli tidak ditemukan peningkatan daya dukung tanah 
sedangkan pada tanah gambut yang telah dimodifikasi semen $15 \%$ dan serbuk batu bata $20 \%$ mengalami kenaikan nilai CBR Laboratorium sebesar $25.88 \%$. Jadi tanah gambut yang telah dimodifikasi tersebut dapat diaplikasikan sbagai tanah subgrade di lapangan

\section{Saran}

Pelaksanaan pemadatan tanah sebaiknya dilakukan sebelum musim penghujan tiba, karena sifat tanah gambut yang mudah menyerap air ketika musim penghujan dan dapat menghambat proses pelaksanaan pekerjaan pemadatan tanah yang sedang berlangsung.

\section{DAFTAR PUSTAKA}

Bowles, E. Joseph, 1986. "Sifat - Sifat Fisis Dan Geoteknis Tanah ( Mekanika Tanah )", Penerbit Erlangga. Jakarta Pusat.

Christady Hardiyatmo, Hary 2002. "Mekanika Tanah I", Gadjah Mada University Press, Yogyakarta.

Coulter, 1975. Sifat hidrofobik gambut dari gambut kering adalah karna adanya lapisan seperti resing yang terbentuk pada waktu pengeringan.

Craig, 1991. Tanah adalah akumulasi mineral yang tidak mempunyai atau lemah ikatan antar partikel nya, yang terbentuk karna pelapukan karna pelapukan dari batuan.

Das, M. Braja, 1994. "Mekanika Tanah (Prinsip - Prinsip Rekayasa Geoteknis)", Jilid I, Erlangga . Jakarta.

Das, 1995. Minerial yang terdiri dari agregat mineral padat yang tidak tersementasi satu sama lain dari bahan organic.

Das, M. Braja, 1998. "Mekanika Tanah”, Jilid I, Erlangga . Jakarta ,1987.”Petunjuk Perencanaan Tebal Perkerasan Lentur Jalan Raya Dengan Metode Analisa Komponen, SKBI.2.3.26.1987,UDC.625.73 (02),SNI 1732-1989-F". Yayasan Badan Penerbitan P.U, Jakarta. 1986."AASHTO Guide For Design of Pavement Structures 1986", American Association of State Highway and Transportation Officials, Washington,D.C.

Dunn, 1980. Tanah termasuk semua bahan, organik, dan organik yang ada di atas lapisan batuan tetap.

Hendarsin, Shirley L, 2000. "Perencanaan Teknik Jalan Raya", Politeknik Bandung, Bandung. Soekoto, Imam, 1984."Mempersiapkan Lapisan Dasar Kontruksi", Badan Penerbit Pekerjaan Umum, Jakarta.

Noor, 2001. Penurunan kemampuan gambut yang mengalami kekeringan dalam menyerap air akibat terbentuk nya penahan air. 